\title{
ANALISIS OPTIMALISASI FAKTOR-FAKTOR PRODUKSI JAMBU AIR DALHARI PADA KELOMPOK TANI RUKUN KECAMATAN BERBAH KABUPATEN SLEMAN
}

\author{
Optimization Analysis of Dalhari Rose Apple Production Factor \\ in Rukun Farmers Group Berbah District Sleman Regency
}

\author{
Helmi Pradana Widan*, Ni Made Suyastiri, Siti Hamidah \\ Program Studi Agribisnis Fakultas Pertanian \\ Universitas Pembangunan Nasional "Veteran" Yogyakarta
}

Jl. SWK 104, Condong Catur, Depok, Sleman, Yogyakarta, Indonesia 55283

Email korespondensi : helmipradana25@gmail.com

Diterima tanggal : 25 Juli 2019 ; Disetujui tanggal : 15 Oktober 2019

\begin{abstract}
This research was conducted in the Rukun Farmers Group in Berbah District, Sleman Regency. This research aimed to: 1) analyze the factors that affecting the dalhari rose apple production, 2) analyze the optimalization of the production factor utilization of dalhari rose apple farming business. This research used descriptive method. The implementation method was the survey method. The method of determine the location used purposive method. The method of taking respondents used the saturated sample method (census). The data used in this research were primary data and secondary data. Techniques of data collection were obtained by observation, interviews, questionnaires and documentation. The analysis technique used Cobb-Douglas analysis to analyze the production factors which consists of land area, the amount of the plants, labor, organic fertilizer and NPK fertilizers as well as the price efficiency for the optimal utilization input. The results of the research showed that 1) production factors consists of land area, the amount of the plant, labor, organic fertilizers NPK fertilizers were affecting the dalhari rose apple production. 2) use of production factors consists of land area, the amount of the plants, labor, organic fertilizers and NPK fertilizer were not optimal yet.
\end{abstract}

Keywords : Dalhari rose apple, Optimization, Production

\begin{abstract}
ABSTRAK
Penelitian ini dilakukan di Kelompok Tani Rukun Kecamatan Berbah, Kabupaten Sleman. Tujuan penelitian ini adalah : 1) menganalisis faktor-faktor yang mempengaruhi produksi jambu air dalhari 2) menganalisis optimalisasi penggunaan faktor-faktor produksi pada usahatani jambu air dalhari. Penelitian ini menggunakan metode deskriptif. Metode pelaksanaan penelitian menggunakan metode survei. Metode penentuan lokasi menggunakan metode purposive. Metode pengambilan responden menggunakan metode sampel jenuh (sensus). Macam
\end{abstract}


data yang digunakan berupa data primer dan data sekunder. Teknik pengumpulan data yaitu observasi, wawancara, kuesioner, dan dokumentasi. Teknik analisis yang digunakan adalah analisis fungsi produksi Cobb-Douglas untuk analisis faktor produksi yang terdiri dari luas lahan, jumlah tanaman, tenaga kerja, pupuk organik, dan pupuk NPK serta efisiensi harga untuk analisis penggunaan input yang optimal. Hasil penelitian menunjukkan bahwa 1) faktor - faktor produksi luas lahan, jumlah tanaman, tenaga kerja, pupuk organik dan pupuk NPK berpengaruh terhadap produksi jambu air dalhari 2) penggunaan faktor - faktor produksi luas lahan, jumlah tanaman, tenaga kerja, pupuk organik dan pupuk NPK di belum optimal.

Kata Kunci : Jambu Air Dalhari, Optimalisasi, Produksi

\section{PENDAHULUAN}

Jambu Air Dalhari merupakan salah satu varietas jambu air dari spesies Syzgium samarangense. Usahatani Jambu Air Dalhari sekarang semakin berkembang di Kabupaten Sleman khususnya di Kecamatan Berbah. Jambu Air Dalhari saat ini menjadi salah satu buah unggulan di Kabupaten Sleman selain salak pondoh. Jambu Air Dalhari pada awalnya ditanam dengan tujuan untuk tanaman peneduh di pekarangan dan buahnya hanya dikonsumsi sendiri. Namun sekarang tanaman ini justru menjadi intensifikasi lahan pekarangan. Budidaya buah tersebut kini menjadi usahatani yang mampu memberikan sumbangan bagi perekonomian rumah tangga petani (Anjani, 2014).

Kelompok Tani Rukun merupakan salah satu kelompok tani yang melakukan budidaya Jambu Air Dalhari. Kelompok Tani Rukun berlokasi di Dusun Krasaan Desa Jogotirto Kecamatan Berbah Kabupaten Sleman. Jumlah anggota Kelompok Tani Rukun hingga saat ini mencapai 27 orang. Dusun Jogotirto merupakan salah satu sentra produksi Jambu Air Dalhari di Kabupaten Sleman. saat ini hampir setiap rumah di Desa Jogotirto khususnya Dusun Krasaan terdapat pohon jambu air dalhari. Total keseluruhan pohon jambu air dalhari yang terdaftar di Kelompok Tani Rukun mencapai 372 pohon dengan rata- rata produktivitas $500 \mathrm{~kg} /$ pohon.

Jambu air dalhari terbagi menjadi 4 grade yaitu grade super, grade $\mathrm{A}$, grade B, dan grade C. Grade super dalam 1 kilogram berisi 6 - 7 buah dijual dengan harga petani Rp 17.000/kg, grade A berisi 8 - 10 buah dalam 1 kilogram 
Widan et.al. / Jurnal Dinamika Sosial Ekonomi Vol.20 No.2, Desember 2019

dijual dengan harga petani Rp 15.000/kg, grade B berisi 11 - 12 buah dalam 1 kilogram dijual dengan harga $\mathrm{Rp} 12.000 / \mathrm{kg}$, dan grade $\mathrm{C}$ berisi 13-14 buah dalam 1 kilogram dijual dengan harga Rp 8.000/kg. Selain itu juga terdapat jambu air dalhari yang tidak termasuk dalam grade tersebut, yaitu jambu yang tidak di bungkus (brongsong) dijual dengan harga Rp 5.000/kg (Aini. 2017).

Lahan merupakan faktor produksi inti dalam usahatani. Luas penguasaan lahan pertanian merupakan suatu yang sangat penting dalam proses produksi (Rusdi, 2017). Luas lahan yang dikelola oleh petani akan sangat berpengaruh pada jumlah produksi jambu air dalhari. Luas lahan yang dimiliki oleh setiap petani untuk budidaya jambu air dalhari berbeda-beda. Selain itu, jumlah tanaman yang dibudidayakan petani dalam luas lahan yang sama jumlah tanamannnya berbeda.

Faktor produksi tenaga kerja, merupakan faktor produksi yang penting dan perlu diperhatikan dalam proses produksi dalam jumlah yang cukup bukan saja dilihat dari tersedianya tenaga kerja tetapi juga kualitas dan macam tenaga kerja perlu diperhatikan. Tenaga kerja yang digunakan di Kelompok Tani Rukun berasal dari tenaga kerja keluarga dan tenaga kerja luar keluarga. Namun beberapa petani jambu air dalhari sudah berumur lebih dari 60 tahun. Hal ini berpengaruh terhadap kinerjanya yang menyebabkan menjadi kurang cekatan.

Meningkatkan produksi jambu air dalhari juga harus memperhatikan faktor penggunaan pupuk. Semakin optimal penggunaan pupuk maka semakin optimal hasil produksi jambu air dalhari. Dalam budidaya jambu air dalhari, Kelompok Tani Rukun menggunakan 2 jenis pupuk yaitu, pupuk organik dan pupuk NPK. Namun dalam menggunakan pupuk, para petani tidak sesuai dengan ketentuan dari dinas pertanian. Sehingga menyebabkan hasil produksi jambu air dalhari yang kurang maksimal.

Produksi merupakan proses perubahan dari beberapa input menjadi output. Dengan penegertian tersebut dapat diketahui bahwa kegiatan produksi merupakan hasil kombinasi dari beberapa input untuk menghasilkan ouput. Analisis pengaruh input terhadap output dapat dijelaskan dalam suatu fungsi produksi. Fungsi produksi yang biasa digunakan yaitu fungsi produksi Cobb Douglas. Fungsi Cobb Douglas merupakan persamaan yang menyatakan pengaruh input yang digunakan 
terhadap produksi yang dihasilkan (Amalia, 2014). Secara umum, fungsi Cobb Douglas dapat dituliskan sebagai berikut :

$$
\mathrm{Y}=\mathrm{aX}_{1}^{\mathrm{b}_{1}} \mathrm{X}_{2}^{\mathrm{b}_{2}} \ldots \mathrm{X}_{\mathrm{i}}^{\mathrm{b}_{\mathrm{i}}} \ldots \mathrm{X}_{\mathrm{n}}^{\mathrm{b}_{\mathrm{n}}} \mathrm{e}^{\mathrm{u}}
$$

Menurut Soekartawi (2016), optimalisasi penggunaan faktor produksi pada prinsipnya adalah bagaimana menggunakan faktor produksi tersebut seefisien mungkin. Dikatakan optimal apabila nilai produk marginal sama dengan harga faktor produksi yang bersangkutan. Dengan diketahuinya nilai optimal faktor produksi maka Kelompok Tani Rukun diharapkan dapat mengambil keputusan atau langkah yang tepat guna menunjang hasil produksi Jambu Air Dalhari. Berdasarkan permasalahan yang ada, maka penelitian ini bertujuan untuk menganalisis faktor-faktor yang mempengaruhi produksi Jambu Air Dalhari dan menganalisis optimalisasi penggunaan faktor - faktor produksi pada usahatani Jambu Air Dalhari di Kelompok Tani Rukun Kecamatan Berbah, Kabupaten Sleman.

\section{METODE PENELITIAN}

Penelitian dilakukan di Kelompok Tani Rukun yang berlokasi di Desa Jogotirto, Kecamatan Berbah, Kabupaten Sleman. Metode dasar yang digunakan adalah metode deskriptif. Menurut Sugiyono (2016) metode deskriptif adalah metode yang digunakan untuk menganalisis data dengan cara mendeskripsikan data yang telah terkumpul sebagaimana adanya tanpa bermaksud membuat kesimpulan yang berlaku untuk umum atau generalisasi. Metode pelaksanaan penelitian ini adalah survei. Metode survei adalah penyelidikan yang diadakan untuk memperoleh fakta - fakta dari gejala - gejala yang ada dan mencari keterangan - keterangan secara faktual, baik tentang intitusi sosial, ekonomi, atau politik dari suatu kelompok ataupun suatu daerah (Sugiyono, 2016). Metode penentuan lokasi menggunakan metode purposive, yaitu metode penentuan tempat yang secara sengaja berdasarkan pertimbangan tertentu (Sugiyono, 2016). Metode pengambilan responden menggunakan metode sampling jenuh atau sensus, yang artinya seluruh populasi digunakan sebagai sampel. Jenis data yang digunakan 
Widan et.al. / Jurnal Dinamika Sosial Ekonomi Vol.20 No.2, Desember 2019

adalah data primer dan sekunder. Sumber data berasal dari Asosiasi Jambu Air Dalhari Sembada, Kelompok Tani Rukun, buku pustaka, dan internet. Metode pengumpulan data yang digunakan yaitu observasi, wawancara, kuesioner, dan dokumentasi.

Metode analisis pengaruh penggunaan faktor-faktor produksi terhadap hasil produksi pada usahatani Jambu Air Dalhari menggunakan fungsi produksi Cobb-Douglas. Fungsi produksi Cobb-Douglas merupakan bentuk persamaan regresi non linier yang dapat ditulis sebagai berikut :

$\mathrm{Y}=\mathrm{aX}_{1}{ }^{\mathrm{b} 1} \mathrm{X}_{2}{ }^{\mathrm{b} 2} \mathrm{X}_{3}{ }^{\mathrm{b} 3} \mathrm{X}_{4}{ }^{\mathrm{b} 4} \mathrm{X}_{5}{ }^{\mathrm{b} 5}$

Keterangan :

$\mathrm{Y}=$ produksi jambu air dalhari $(\mathrm{kg})$

a $\quad=$ intersep

$\mathrm{X}_{1} \quad$ = luas lahan $\left(\mathrm{m}^{2}\right)$

$\mathrm{X}_{2} \quad=$ jumlah tanaman (batang)

$\mathrm{X}_{3} \quad=$ tenaga kerja (hok)

$\mathrm{X}_{4} \quad=$ pupuk organik $(\mathrm{kg})$

$\mathrm{X}_{5} \quad=$ pupuk NPK $(\mathrm{kg})$

$\mathrm{b} \quad=$ koefisien regresi

Kemudian untuk mengetahui pengaruh faktor - faktor produksi secara bersama - sama terhadap produksi Jambu Air Dalhari digunakan Uji F. Sedangkan untuk mengetahui pengaruh dari masing - masing faktor produksi terhadap produksi Jambu Air Dalhari digunakan Uji t.

Metode analisis optimalisasi menggunakan efisiensi harga. Efisiensi penggunaan input dihitung dengan menggunakan indikator Nilai Produk Marginal. Menurut Mamondol (2017), penggunaan input dikatakan optimal apabila nilai produk marginal sama dengan harga faktor produksi yang bersangkutan. Secara sistematis dapat ditulis sebagai berikut:

$$
\frac{\mathrm{NPMX}_{\mathrm{i}}}{\mathrm{PX}_{\mathrm{i}}}=\mathrm{k} ; \mathrm{k}=1
$$

Rasio NPMx / Px > 1 menunjukkan bahwa penggunaan input dikatakan belum optimal sehingga masih perlu ditambah penggunaannya. Rasio NPMx / Px $=1$ menunjukkan bahwa penggunaan input sudah optimal. Sedangakan rasio NPMx / Px $<1$ menunjukkan bahwa penggunaan input tidak optimal sehingga perlu dikurangi penggunaannya. 


\section{HASIL DAN PEMBAHASAN}

\section{Analisis Faktor - faktor yang Mempengaruhi Produksi Jambu Air Dalhari}

Berdasarkan faktor - faktor produksi yang telah teridentifikasi, maka faktor produksi yang diduga berpengaruh terhadap produksi jambu air dalhari yaitu, luas lahan (X1), jumlah tanaman (X2), tenaga kerja (X3), pupuk organik (X4), dan pupuk NPK (X5). Pengaruh faktor - faktor produksi dengan produksi jambu air dalhari dapat dilihat dari fungsi produksi Cobb-Douglas. Tabel 1 berikut menggambarkan hasil analisis regresi faktor - faktor produksi yang mempengaruhi produksi jambu air dalhari.

Tabel 1. Hasil Analisis Regresi Faktor - faktor Produksi Jambu Air Dalhari

\begin{tabular}{llr}
\multicolumn{1}{c}{ Variabel } & $\mathrm{b}$ & Sig. t \\
\hline Konstanta & $4,692^{*}$ & 0,000 \\
Luas Lahan (X1) & $0,163^{*}$ & 0,000 \\
Jumlah Tanaman (X2) & $0,349^{*}$ & 0,005 \\
Tenaga Kerja (X3) & $0,238^{*}$ & 0,001 \\
Pupuk Organik (X4) & $0,149^{*}$ & 0,000 \\
Pupuk NPK (X5) & $0,171^{* *}$ & 0,042 \\
\hline Sig. F & $0,000^{*}$ & \\
Adjusted R & 0,998 & \\
\hline
\end{tabular}

Sumber : Analisis Data Primer 2019

Keterangan : ${ }^{*}=$ signifikan pada $\alpha=1 \%$ $* *=$ signifikan pada $\alpha=5 \%$

Berdasarkan Tabel 1 maka dapat diketahui persamaan regresi linear berganda :

$\ln Y=4,692+0,163 \ln X_{1}+0,349 \ln X_{2}+0,238 \ln X_{3}+0,149 \ln X_{4}+0,171 \ln X_{5}$

Untuk menduga hubungan antara produksi (Y) sebagai variabel terikat dengan faktor produksi $\left(\mathrm{X}_{\mathrm{i}}\right)$ yang diduga mempengaruhi $\mathrm{Y}$ sebagai variabel bebas digunakan fungsi produksi Cobb-Douglas yang diperoleh dari anti ln (logaritma natural) persamaan regresi linier berganda diatas. Sehingga diperoleh persamaan Cobb-Douglas sebagai berikut : 
Widan et.al. / Jurnal Dinamika Sosial Ekonomi Vol.20 No.2, Desember 2019

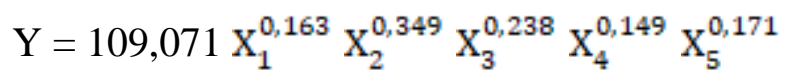

Berdasarkan persamaan tersebut dapat diketahui bahwa total nilai elastisitas produksi adalah 1,07 yang diperoleh dari nilai total koefisien regresi yang berarti elastisitas produksi berada pada daerah I.

Nilai koefisien regresi luas lahan (X1) sebesar 0,163. Dapat diartikan bahwa setiap penambahan $1 \%$ luas lahan akan meningkatkan produksi sebesar $0,163 \%$ sedangkan faktor lainnya dianggap tetap. Nilai koefisien regresi jumlah tanaman (X2) sebesar 0,349. Dapat diartikan bahwa setiap penambahan $1 \%$ jumlah tanaman akan meningkatkan produksi sebesar $0,349 \%$ sedangkan faktor lainnya dianggap tetap. Nilai koefisien regresi sebesar tenaga kerja (X3) 0,238. Dapat diartikan bahwa setiap penambahan $1 \%$ tenaga kerja akan meningkatkan produksi sebesar $0,238 \%$ sedangkan faktor lainnya dianggap tetap. Nilai koefisien regresi pupuk organik (X4) sebesar 0,149. Dapat diartikan bahwa setiap penambahan $1 \%$ pupuk organik akan meningkatkan produksi sebesar $0,149 \%$ sedangkan faktor lainnya dianggap tetap. Nilai koefisien regresi pupuk NPK (X5) sebesar 0,171. Dapat diartikan bahwa setiap penambahan $1 \%$ pupuk NPK akan meningkatkan produksi sebesar $0,171 \%$ sedangkan faktor lainnya dianggap tetap.

Berdasarkan Tabel 1 dapat diketahui bahwa nilai koefisien determinasi (adj. R Square) adalah 0,997 atau dapat dikatakan bahwa 99,7\% produksi jambu air dalhari dapat dijelaskan oleh faktor produksi yang diteliti, yaitu luas lahan, jumlah tanaman, tenaga kerja, pupuk organik, dan pupuk NPK. Sedangkan 0,3\% produksi jambu air dalhari dijelaskan oleh faktor lain yang tidak termasuk dalam variabel peneltian.

Berdasarkan hasil uji $\mathrm{F}$ dapat diketahui bahwa nilai signifikan bernilai 0,000 yang lebih kecil dari nilai $\alpha=0,01(0,000<0,01)$, sehingga Ho ditolak dan Ha diterima yang artinya secara bersama - sama variabel luas lahan (X1), jumlah tanaman (X2), tenaga kerja (X3), pupuk organik (X4), dan pupuk NPK (X5) berpengaruh nyata terhadap produksi jambu air dalhari (Y).

Berdasarkan hasil analisis hubungan faktor produksi, diketahui bahwa faktor produksi luas lahan berpengaruh terhadap hasil produksi jambu air dalhari. Nilai koefisien regresi luas lahan sebesar 0,163 yang dapat diartikan bahwa 
penambahan $1 \%$ luas lahan akan meningkatkan produksi sebesar 0,163\% sedangkan faktor lainnya dianggap tetap. Sehingga petani masih bisa menambah luas lahan untuk meningkatkan hasil produksi jambu air dalhari. Berdasarkan hasil analisis regresi parsial dapat diketahui bahwa nilai signifikasi luas lahan sebesar 0,000 yang lebih kecil dari nilai $\alpha=1 \%(0,000<0,01)$. Artinya bahwa luas lahan berpengaruh secara nyata terhadap hasil produksi jambu air dalhari. Lahan merupakan hal utama dalam usahatani, sesuai dengan teori yang ada jika semakin besar luas lahan maka semakin besar produksi yang di hasilkan (Ambarita dan Kartika 2015).

Berdasarkan hasil analisis hubungan faktor produksi, diketahui bahwa faktor produksi jumlah tanaman berpengaruh terhadap hasil produksi jambu air dalhari. Nilai koefisien regresi jumlah tanaman sebesar 0,349 yang dapat diartikan bahwa penambahan $1 \%$ batang tanaman akan meningkatkan produksi sebesar $0,349 \%$ sedangkan faktor lainnya dianggap tetap. Sehingga petani masih bisa menambah jumlah tanaman jambu air dalhari untuk meningkatkan hasil produksi jambu air dalhari. Berdasarkan hasil analisis regresi parsial dapat diketahui bahwa nilai signifikasi jumlah tanaman sebesar 0,005 yang lebih kecil dari nilai $\alpha=1 \%$ $(0,005<0,01)$. Artinya bahwa jumlah tanaman berpengaruh secara nyata terhadap hasil produksi jambu air dalhari. Jumlah tanaman yang tidak sesuai dengan luas lahan yang ada dapat menyebabkan produksi yang kurang optimal. Menurut Wirawan et al. (2018) jarak tanam juga perlu diperhatikan agar pertumbuhan tanaman dapat seragam sehingga produksinya bisa maksimal, distribusi unsur hara yang merata, efektivitas penggunaan lahan, mengetahui kebutuhan benih, memudahkan pemeliharaan, seperti penyiangan, pembumbunan, pemupukan, pengairan,dan pengendalian hama penyakit.

Berdasarkan hasil analisis hubungan faktor produksi, diketahui bahwa faktor produksi tenaga kerja berpengaruh terhadap hasil produksi jambu air dalhari. Nilai koefisien regresi tenaga kerja sebesar 0,238 yang dapat diartikan bahwa penambahan $1 \%$ tenaga kerja akan meningkatkan produksi sebesar 0,238 $\%$ sedangkan faktor lainnya dianggap tetap. Sehingga petani masih bisa menambah jumlah tenaga kerja untuk meningkatkan hasil produksi jambu air 
Widan et.al. / Jurnal Dinamika Sosial Ekonomi Vol.20 No.2, Desember 2019

dalhari. Berdasarkan hasil analisis regresi parsial dapat diketahui bahwa nilai signifikasi tenaga kerja sebesar 0,001 yang lebih kecil dari nilai $\alpha=1 \%(0,001<$ 0,01). Artinya bahwa tenaga kerja berpengaruh secara nyata terhadap hasil produksi jambu air dalhari. Hal tersebut sesuai dengan pernyataan Dewi dan Yuliarmi (2017), yang menyatakan bahwa tenaga kerja adalah faktor produksi yang berperan penting dalam proses produksi pertaian. Semakin banyak tenaga kerja yang digunakan dalam proses produksi, maka akan semakin banyak pula output yang dapat dihasilkan dalam proses produksi. Tenaga kerja dalam budidaya jambu air dalhari yang sudah produktif sangat diperlukan terutama untuk kegiatan pemupukan, pemangkasan, pembrongsongan, serta pemanenan. Selain itu untuk meningkatkan keuntungan dapat juga mengganti tenaga kerja luar keluarga dengan tenaga kerja keluarga supaya menghemat upah yang digunakan untuk pembayaran tenaga kerja luar keluarga.

Berdasarkan hasil analisis hubungan faktor produksi, diketahui bahwa faktor produksi pupuk organik berpengaruh terhadap hasil produksi jambu air dalhari. Nilai koefisien regresi pupuk organik sebesar 0,149 yang dapat diartikan bahwa penambahan $1 \%$ pupuk organik akan meningkatkan produksi sebesar $0,149 \%$ sedangkan faktor lainnya dianggap tetap. Sehingga petani masih bisa menambah jumlah pupuk organik untuk meningkatkan hasil produksi jambu air dalhari. Berdasarkan hasil analisis regresi parsial dapat diketahui bahwa nilai signifikasi pupuk organik sebesar 0,000 yang lebih kecil dari nilai $\alpha=1 \%(0,000$ $<0,01)$. Artinya bahwa pupuk organik berpengaruh secara nyata terhadap hasil produksi jambu air dalhari. Hal tersebut sesuai dengan penelitian Alavan et al. (2015) yang menyatakan bahwa, penggunaan pupuk yang tepat dapat mendukung pertumbuhan tanaman dan dapat menjaga keseimbangan lingkungan. Pemberian pupuk organik dimaksudkan untuk menambah jumlah hara yang dibutuhkan oleh tanaman. Semakin banyak unsur hara dalam tanah menyebabkan tanah menjadi subur, sehingga produksi jambu air dalhari juga akan meningkat. Maka dari itu, petani diharapkan memperhatikan jumlah pupuk organik yang harus diberikan pada tanaman jambu air dalhari sesuai dengan ketentuan dari dinas pertanian yaitu sebanyak 40 - $60 \mathrm{~kg}$ per batang. Selain itu, petani juga harus memperhatikan 
frekuensi pemberian pupuk organik yang telah ditentukan oleh dinas pertanian yaitu sebanyak 2 kali setahun pada awal musim panen dan setelah musim panen.

Berdasarkan hasil analisis hubungan faktor produksi, diketahui bahwa faktor produksi pupuk NPK berpengaruh terhadap hasil produksi jambu air dalhari. Nilai koefisien regresi pupuk NPK sebesar 0,171 yang dapat diartikan bahwa penambahan $1 \%$ pupuk NPK akan meningkatkan produksi sebesar 0,171 $\%$ sedangkan faktor lainnya dianggap tetap. Berdasarkan hasil analisis regresi parsial dapat diketahui bahwa nilai signifikasi pupuk NPK sebesar 0,042 yang lebih kecil dari nilai $\alpha=5 \%(0,042<0,05)$. Artinya bahwa pupuk NPK berpengaruh secara nyata terhadap hasil produksi jambu air dalhari. Pupuk NPK merupakan pupuk kimia yang terdiri dari unsur Nitrogen $(\mathrm{N})$, Phosphor $(\mathrm{P})$, dan Kalium (K). Petani menggunakan pupuk NPK secara tidak rutin dan jumlah yang digunakan masih jauh dibawah dari ketentuan yang diberikan oleh dinas pertanian. Sehingga perlu adanya peningkatan jumlah pupuk NPK yang diberikan namun tidak boleh melebihi batas yang telah ditentukan.

\section{Analisis Optimalisasi Penggunaan Faktor - faktor Produksi}

Menurut Soekartawi (2016), optimalisasi penggunaan faktor produksi pada prinsipnya adalah bagaimana menggunakan faktor produksi tersebut seefisien mungkin. Berdasarkan hasil analisis optimalisasi pada tabel 2 menunjukkan bahwa faktor luas lahan, jumlah tanaman, tenaga kerja, pupuk organik, dan pupuk NPK memiliki rasio Nilai Produk Marginal $\left(\mathrm{NPMx}_{\mathrm{i}}\right)$ dengan harga input masingmasing produksi $\left(\mathrm{Px}_{\mathrm{i}}\right)$ lebih dari 1 yang artinya bahwa penggunaannya belum optimal atau masih perlu ditambahkan.

Hasil analisis optimalisasi luas lahan diperoleh hasil 40,22 yang artinya faktor produksi luas lahan belum optimal. Sehingga luas lahan perlu ditambahkan agar diperoleh penerimaan yang lebih besar. Karena selama ini lahan yang digunakan petani untuk budidaya Jambu Air Dalhari hanya lahan di pekarangan rumah yang jumlahnya terbatas. Oleh karena itu untuk meningkatakan produksi bisa dilakukan dengan cara melakukan budidaya Jambu Air Dalhari di lahan kosong yang tidak terpakai. 
Widan et.al. / Jurnal Dinamika Sosial Ekonomi Vol.20 No.2, Desember 2019

Tabel 2. Hasil Analisis Optimalisasi Faktor - faktor Produksi Jambu Air Dalhari

\begin{tabular}{lccccccc}
\hline \multicolumn{1}{c}{ Variabel } & $\mathrm{X}$ & $\mathrm{PRx}$ & $\mathrm{bx}$ & $\mathrm{PM}$ & $\mathrm{NPM}$ & $\begin{array}{c}\text { NPM/Px } \\
(\mathrm{k})\end{array}$ & $\begin{array}{c}\mathrm{X} \\
\text { optimal }\end{array}$ \\
\hline $\begin{array}{l}\text { Luas } \\
\text { lahan (X1) }\end{array}$ & 236,67 & 28,48 & 0,163 & 4,64 & $68.379,52$ & 40,22 & 9519,68 \\
$\begin{array}{l}\text { Jumlah } \\
\text { tanaman (X2) }\end{array}$ & 13,78 & 489,22 & 0,349 & 170,74 & $2.514 .906,31$ & 50,30 & 693,01 \\
$\begin{array}{l}\text { Tenaga } \\
\text { kerja (X3) }\end{array}$ & 111,33 & 60,54 & 0,238 & 14,41 & $212.240,03$ & 2,65 & 295,37 \\
$\begin{array}{l}\text { Pupuk } \\
\text { kandang (X4) }\end{array}$ & 328,89 & 20,49 & 0,149 & 3,05 & $44.979,29$ & 44,98 & 14793,47 \\
$\begin{array}{l}\text { Pupuk } \\
\text { NPK (X5) }\end{array}$ & 6,81 & 989,07 & 0,171 & 169,13 & $2.491 .251,71$ & 216,63 & 1476,32 \\
\hline
\end{tabular}

Sumber : Analisis Data Primer 2019

Hasil analisis optimalisasi jumlah tanaman diperoleh hasil 50,30 yang artinya faktor produksi tanaman belum optimal. Sehingga jumlah tanaman perlu ditambahkan agar diperoleh penerimaan yang lebih besar. Berdasarkan kondisi dilapangan, jumlah tanaman yang ada jumlahnya masih relatif sedikit. Hal ini dikarenakan dalam pekarangan tersebut tidak hanya ditanam jambu air dalhari sehingga tanaman jambu air dalhari masih sedikit.

Hasil analisis optimalisasi tenaga kerja diperoleh hasil 2,65 yang artinya faktor produksi tenaga kerja belum optimal. Sehingga tenaga kerja perlu ditambahkan agar diperoleh penerimaan yang lebih besar. Terutama tenaga kerja bagian pembrongsongan yang perlu ditambah, karena proses pembrongsongan juga bersamaan dengan proses penjarangan calon buah dan pada proses ini merupakan proses yang sangat menentukan grade buah jambu air dalhari pada saat panen, sehingga diperlukan curahan tenaga kerja yang lebih intensif.

Hasil analisis optimalisasi pupuk organik diperoleh hasil 44,98 yang artinya faktor produksi pupuk organik belum optimal. Sehingga pupuk organik perlu ditambahkan agar diperoleh penerimaan yang lebih besar. Begitu juga dengan hasil analisis optimalisasi pupuk NPK diperoleh hasil 216,63 yang artinya faktor produksi pupuk NPK belum optimal. Sehingga pupuk NPK perlu ditambahkan agar diperoleh penerimaan yang lebih besar. Hal ini dikarenakan penggunaan pupuk oleh petani jambu air dalhari masih kurang dan belum sesuai 
dengan ketentuan dari dinas pertanian. Sehingga perlu ditingkatkan jumlah takaran pupuknya dan juga perlu diperhatikan frekuensi pemberian pupuk agar sesuai dengan peraturan yang ada.

\section{KESIMPULAN DAN SARAN}

\section{Kesimpulan}

Faktor - faktor produksi luas lahan, jumlah tanaman, tenaga kerja, pupuk organik dan pupuk NPK berpengaruh terhadap produksi jambu air dalhari di Kelompok Tani Rukun Kecamatan Berbah Kabupaten Sleman. Penggunaan faktor - faktor produksi luas lahan, jumlah tanaman, tenaga kerja, pupuk organik dan pupuk NPK di Kelompok Tani Rukun Kecamatan Berbah Kabupaten Sleman belum optimal.

\section{Saran}

Penggunaan faktor produksi luas lahan perlu ditingkatan menjadi 9519,68 $\mathrm{m}^{2}$, jumlah tanaman ditingkatkan menjadi 693,01 batang, tenaga kerja ditingkatkan menjadi 295,37 HOK, pupuk organik ditingkatkan menjadi 14793.47 $\mathrm{kg}$, dan pupuk NPK ditingkatkan menjadi 1476,32 kg agar tercapai kombinasi yang optimal. Budidaya jambu air dalhari sebaiknya dilakukan di lahan yang luas atau di kebun. Namun jika penambahan luas lahan dan jumlah tanaman sulit dilakukan maka dapat diatasi dengan melakukan intensifikasi pertanian. Dinas pertanian sebaiknya lebih mengintensifkan penyuluhan kepada petani tentang manajemen usahatani sehingga produksi jambu air dalhari dapat maksimal.

\section{UCAPAN TERIMA KASIH}

Ucapan terima kasih diberikan kepada Lembaga Penelitian dan Pengabdian Masyarakat Universitas Pembangunan Nasional "Veteran" Yogyakarta atas bantuan dana riset penelitian dalam karya ilmiah ini.

\section{DAFTAR PUSTAKA}

Aini, P.N. 2017. Analisis Nilai Tambah Jambu Air Dalhari Pada Asosiasi Jambu Air Dalhari di Kecamatan Berbah Kabupaten Sleman. Skripsi. Fakultas Pertanian Universitas Pembangunan Nasional "Veteran": Yogyakarta. 
Widan et.al. / Jurnal Dinamika Sosial Ekonomi Vol.20 No.2, Desember 2019

Alavan, A., Rita H., \& Erita H. 2015. Pengaruh Pemupukan Terhadap Pertumbuhan Beberapa Varietas Padi Gogo (Oryza Sativa L.). Jurnal Floratek. 10 (1): 61-68.

Amalia. 2014. Analisis Fungsi Produksi Cobb-Douglas pada Kegiatan Sektor Usaha Mikro di Lingkungan Uin Syarif Hidayatullah Jakarta. Jurnal Signifikan. 3 (1): 45 - 62.

Ambarita, P. \& Nengah K. 2015. Pengaruh Luas Lahan, Pnggunaan Pestisida, Tenaga Kerja, Pupuk Terhadap Produksi Kopi Kecamatan Pekutatan Kabupaten Jembrana. E-Jurnal EP Unud. 4 (7): 746-872.

Anjani, H.D. 2014. Analisis Pendapatan dan Tingkat Kesejahteraan Rumah Tangga Petani Jambu Air Dalhari di Kabupaten Sleman. Skripsi. Fakultas Pertanian Universitas Gadjah Mada: Yogyakarta.

Dewi, I.A.N.U., \& Yuliarmi, N.N. 2017. Pengaruh Modal, Tenaga Kerja, dan Luas Lahan Terhadap Jumlah Produksi Kopi Arabika di Kecamatan Kintamani Kabupaten Bangli. E-Jurnal EP Unud. 6 (6): 1127-1156.

Mamondol, M. R. 2017. Efisiensi Penggunaan Faktor Produksi Tenaga Kerja dan Modal pada Usahatani Kedelai Di Kelurahan Pamona Kecamatan Pamona Puselemba Kabupaten Poso. Jurnal Envira. 2 (2): 1 - 7.

Soekartawi. 2016. Agribisnis Teori dan Aplikasinya. Jakarta: RajaGrafindo Persada.

Sugiyono. 2016. Metode Penelitian Kombinasi (Mixed Methods). Bandung: Alfabeta.

Wirawan D.A., Gembong, H., \& Susilowati, Y.E. 2018. Pengaruh Jumlah Tanaman Per Lubang dan Jarak Tanam Terhadap Hasil Tanaman Kacang Tanah (Arachis Hypogea, L.) Var. Kancil. Jurnal Ilmu Pertanian Tropika dan Subtropika. 3 (1): 5-8. 